July 2011

\title{
Reaching Escape Velocity and the Purpose of SLIS Student Research Journal
}

Anthony Bernier

San Jose State University, anthony.bernier@sjsu.edu

Follow this and additional works at: https://scholarworks.sjsu.edu/ischoolsrj

Part of the Library and Information Science Commons

\section{Recommended Citation}

Bernier, A. (2011). Reaching Escape Velocity and the Purpose of SLIS Student Research Journal. School of Information Student Research Journal, 1(1). https://doi.org/10.31979/2575-2499.010102 Retrieved from https://scholarworks.sjsu.edu/ischoolsrj/vol1/iss1/2

This article is brought to you by the open access Journals at SJSU ScholarWorks. It has been accepted for inclusion in School of Information Student Research Journal by an authorized administrator of SJSU ScholarWorks. For more information, please contact scholarworks@sjsu.edu. 
Bernier: Reaching Escape Velocity

Reaching Escape Velocity and the Purpose of SLIS Student Research Journal

\author{
Anthony Bernier, Associate Professor \\ San José State University \\ Faculty Advisor \\ SLIS Student Research Journal
}

As we inaugurate and launch our school's new Student Research Journal I want to borrow a term used by our colleagues in physics because it applies to those of us who read, evaluate, edit, and produce research: "escape velocity." In our present context, escape velocity aptly characterizes what all new and original research must achieve in order contribute to our base of knowledge. More specifically escape velocity represents the intellectual 'breaking free' of the gravitational pull of current scholarship in library and information science and the charting of new vistas, identification of new questions, and the proposal of new answers as we advance our knowledge and insights about what comes next. Escape velocity is the demonstration that an author has mastered what the scholarship currently says, has creatively identified what they feel should come next, and has a few recommendations of ways in which to get there.

So the question before us as we launch our new journal is this: How can students reach escape velocity through the submissions selected for publication in the $S R J$ and within the contexts of our LIS and archival concerns? The answer, simply put, is to build upon and advance our work through the recognized patterns of academic literature, discourse, and practice.

This naturally raises the question: "What constitutes academic literature and discourse?" In this brief space I attempt to outline the salient features of these patterns largely within the vehicle of a "literature review." As someone interested in reading or editing or evaluating or even publishing in the $S R J$ you should know that these are also among the criteria used by our Editorial Team as it conducts the double-blind peer review process.

Among the best vehicles in which to achieve escape velocity, although certainly not the only vehicle, remains a successful literature review. The literature review is key to any scholarly field of study in its capacity to accurately assemble and synthesize a sense of "what's going on" about a particular topic at a particular time. This would be the "gravitational pull" of a particular topic... it grounds and locates the current center of scholarly achievement and answers the question "Where is the field?" on a defined subject or topical concern. Then, armed with this assessment, an author nominates new and exploratory research questions to build upon that scholarship, thus advancing our profession's knowledge and propelling the topic into escape velocity. 


\section{SLIS Student Research Journal}

July 2011, Vol.1, Iss. 1

More specifically, a literature review performs two functions: first, to frame and ground one's discovery, analysis, and synthesis of the relevant secondary literature produced by scholars about a particular topic; and two, to inaugurate new questions, concerns, and inquiry beyond what we already know from that scholarship. Note that while a literature review does include applying reference skills and can be characterized as "doing research" on something, one must distinguish between "searching" for and discovery of the scholarly literature on a topic (through "tertiary" or reference sources and "secondary research") on the one hand, from conducting "primary research," which involves the collection and analysis of data and primary sources through the execution of explicit research methodology on the other. Literature reviews are constituted nearly entirely by tertiary (reference sources) and secondary research. It is common for students to confuse these terms so be aware that the same term "research" is often casually confused with conducting "reference" or search and discovery activities. They are not the same.

While it is true that there is no "standard" or formal "format" for a topical literature review, there are persistent scholarly practices widely viewed as more or less successful. The following recommended basic steps and tasks lead to producing an authentic and scholarly secondary literature review that, upon conclusion, would justifiably demonstrate that a researcher knows "what's going on" about a particular research topic, and is thereby also entitled to launch new questions and concerns that may lead to further original research.

\section{Stepping Through to Escape Velocity}

An author writing a literature review capable of reaching escape velocity begins by consulting updated and relevant "tertiary tools" (also known as reference tools) to identify the best search terms, vocabulary, and descriptors for a particular topic. These terms then inform the searching of appropriate indexes or databases (either print or electronic, depending on the topic and approach). Here search syntax strategies are deployed (using "Boolean operators," for instance, to expand, delimit, and refine searches) including searches of title words from relevant works; searching by author (if an authority); mining footnotes and endnotes of pertinent works; book reviews; and other published literature reviews, to name the most frequently employed methods.

Once the recent and relevant scholarship has been identified in scholarly monographs and peer-reviewed journal articles the intellectual labor shifts from searching and discovery to analysis. While space does not allow for a detailed treatment of all of the analytical aspects required of a quality literature review some key features deserve special attention. Researchers must identify the core 
question - the "super-ordinate" question lying at the heart of each piece of scholarly writing. It is these core questions that drive research forward.

Another feature in building a literature review toward escape velocity is identifying each author's thesis as the single, overarching answer to his or her core question. Scholarly writing contains both - a core question and a thesis statement that together constitute the essential components for comparing and contrasting scholarly works, and help establish and propel one's new and current analysis of "where the field is" - of where the center of gravity lies. More important still is that together these two components provide comparable analytical stepping stones to the next step.

Once each of the relevant sources has been examined and the respective core questions and theses have been determined the time comes to synthesize these into a new framework. When examined side by side, how do all the works under review compare and contrast in terms of these essential components? How do respective works relate to, connect with, or contrast the other important works on the same topic? What core or over-arching questions emerge from all of the works when considered as a whole body of work? What thesis or answer to that core question emerges, again, from all of these works together?

Also helpful in contextualizing the literature is identifying several other aspects of the scholarship under review. Among these additional aspects are identifying the subordinate questions advanced by respective authors as well as their companion sub-theses. These components commonly appear within the contexts of sub-sections and sub-headings in longer works. What research methods were deployed in collecting or amassing and analyzing the data in the research? What methodological benefits and/or liabilities were evident and how were these treated in the respective works? How did authors respond to those liabilities?

This process of comparing and contrasting and distilling and compressing essential components of relevant scholarship into analytical categories constitutes the process of "synthesis." It is only upon completion of the synthesis of "where the field is" that one becomes qualified to nominate new and original questions to advance the field's knowledge base.

Note: This synthesis step in reaching escape velocity marks a significant difference between a literature review and an annotated bibliography. The former treats all the works collectively as one body of knowledge while the latter simply treats each item sequentially and individually.

Formulating new questions might come from observing gaps in the current literature (a user group or experience thus far ignored or slighted in the research 


\section{SLIS Student Research Journal \\ July 2011, Vol.1, Iss. 1}

literature; a new technological procedure or process not yet recognized; a theoretical concern not addressed, among many other possibilities). Alternatively, new questions can come from observing that the previous scholarship has overemphasized a group, an experience, a process, or theory.

Some students may better recognize synthesizing using other terms. The phrase "red thread," for instance, may be recognized by some to represent a common "theme" running through the material under examination. The caution here is that a "theme" is not a question, nor is a "red thread" a thesis statement. However, "red thread" does signal a dimension of commonality arising from a comprehensive examination of all the works in a collection of readings.

Once the new questions have been articulated the author of a successful literature review begins to sort, synthesize, and prioritize them. Which of these new questions combine into a larger concern? Which ones fall off for not being sufficiently large or important enough? Which ones appeal to the researcher as more interesting? Which is the most useful question for the profession to pursue at the present time?

It is only after synthesizing the topic's scholarly literature, and articulating a new and original question, that an author can begin to reach escape velocity. Arrival at a new question based upon the gaps or omissions from previous scholarship is also called making "the turn." "The turn" refers to that moment in a literature review in which the author swiftly characterizes all of the current and relevant scholarship in a brief and sweeping statement, before separating from it and launching off into articulating a new and original core question.

A scholarly literature review declares and demonstrates that the author can defend the originality of a new core question and is thus prepared to engage or recommend original research: collect, evaluate, and examine primary data, and articulate a new thesis in response to that core question.

\section{Moving Toward a New Narrative}

After the analytical steps have been completed the researcher will render the intellectual yield in narrative form. Here the basic rhetorical structure of any academic narrative comes into play: an introduction, supporting paragraphs, and conclusion. And here too literature reviews capable of reaching escape velocity demonstrate some common characteristics.

\section{The Literature Review Introduction}

An introduction includes the announcement of the overall topic, its importance to the field and an explanation of why it is important; it defines key terms; it notes basic features of the literature searching steps; it answers why 
some aspects of a topic were selected for treatment and why others were not; it characterizes the current nature and state of the literature and points out significant landmark studies or scholars; it identifies how the literature review is organized (i.e. identifies sub-topics and sub-questions); it announces the single over-arching (super-ordinate) question; and, without the author having conducted original primary research, a good introduction offers the reader a speculative or "educated guess" as to the answer for that single core question.

Note: Due to the nature of most master degree programs it is important to realize that unless an author has had the opportunity to actually enter the field, collect and analyze original primary data, and render it within the context of established methodological practice (such as might occur in the process of producing a master's-level thesis), presenting original field research will be a difficult challenge to surmount. However, a well-executed and successful literature review does certainly qualify as a legitimate and valuable contribution to our secondary research knowledge.

The importance of both a single over-arching question and a thesis statement emerging from the literature under review appearing prominently in an introduction cannot be overemphasized. Without these essential and synthetic components characterizing the current "state of the field," a literature review cannot achieve its most valuable goal: to demonstrate to the reader that the author's work has reached escape velocity. Without a new core question emerging from the previous scholarship the narrative does not achieve much beyond being a merely descriptive summary "report" of the readings at hand. A literature review that does not offer the reader an over-arching synthetic question, such as "What a recent review of the scholarly LIS literature asks about our culture's view of librarians is...," demonstrates that the author has yet to truly master the covered works.

Note: One might consider the story of the auto mechanic to illustrate the importance of achieving this synthetic "state of the field" view. Say one was to leave one's car with an auto mechanic for the purpose of diagnosing a persistent problem and then return at the end of the day to inquire after the problem. Upon emerging from under the car's hood the mechanic says: "Well, it could be the transmission. Or it could be the muffler. Or it could be the carburetor." After having had the car all day to examine and to arrive only at a mere list of possible problems would not inspire much confidence in the mechanic's ability. A reasonable expectation would have been for the mechanic to identify one problem and offer, at minimum, a strategy or course of action to resolve the issue and seek approval to proceed. What the customer really wants from the mechanic is this: 


\section{SLIS Student Research Journal}

July 2011, Vol.1, Iss. 1

"I've examined the car. Here's the problem. Here's what needs to be done." That is the same thing that readers want from a literature review: "I've examined the literature. Here are the gaps in what needs to be done next. Here's what I think so far."

\section{The Literature Review in Sub-Sections}

After the introduction, the second component of academic execution remains, of course, the body of the essay. The body supports the answer of the essay's core question in parts, that is to say, in sub-sections. Ideally these sub-section parts of the body each contribute a portion to the essay's thesis - in answer to the core question. These sub-sections have taken shape and form through the building of two, three, or sometimes even four groups of secondary sources (identified by the author) that have emerged in the analysis of the recent literature on the topic.

Because a literature review's primary objective is to conclude with the author's version of escape velocity, certain practices appearing in many other kinds of student writing should be viewed differently. One's own opinion, for instance, of a particular topic or subject or author should be clearly delineated from that of the authors' of the secondary literature under review. A literature review must properly and faithfully characterize the core questions and answers to those questions as rendered by their respective authors in order for the analysis to be useful. Second, quotations from the texts under review, especially long block quotes, should appear only sparingly. And, unlike in annotated bibliographies where the uniform demands of meta-data practices should be addressed, major or key scholarly works might well require more space than less influential works in a literature review.

Within each sub-section certain critical analytics should be applied to each secondary source under review, as well as to the group of works in that particular sub-section. Beyond identifying the respective core questions and thesis statements for the works in a particular sub-section, works can be compared and contrasted for strengths and weaknesses, methodological approaches, the effectiveness of the primary data analysis, and any gaps or omissions. No matter the specific criteria used to evaluate each item individually, the conclusion of a sub-section should point the reader back to the essay's overall core question. In other words, the concluding statement in each of the literature review's subsections should point out the commonalities that lead the author to constitute the works under review as a sub-section, and point out why and how these works, when treated together, address the essay's overall core question and contribute to the essay's thesis.

The criteria for assembling a group of secondary works into a sub-section will vary greatly and depend on many factors. Among the more common ways in 
which to group secondary scholarship are by topic or subject of a work's major concern, date or era in which a work was published, the population under examination by a particular work, the institution under examination (for instance, all works on public libraries might indicate a sub-section, while academic libraries might be a second), particular theories or "schools of thought" (authors who believe that archivists treat all their procedures objectively, for instance, versus those who do not believe that is possible or achievable), among many examples. The process of selecting how to group or categorize the works under review constitutes a significant and creative act of intellectual labor. But it is also an essential component in producing a successful literature review.

\section{Concluding a Literature Review}

The third and final component of a literature review is the conclusion. As with the general format of a literature review's structure there may not be a strict "formula" for deploying an effective concluding section but there are components that commonly appear in successful essays. One common feature of a conclusion is how an author draws the sub-sectional components together to contribute to an assessment of the literature's overall core question and to answer that question furnished by each. This practice insures that the essay does not simply repeat the same over-arching question in each sub-section, and rather, provides the reader a sense of dynamic building of new discourse throughout the essay. Drawing together each sub-section in this way also proves to the reader that the essay's author has mastered the recent and relevant literature and is qualified to launch into escape velocity.

It is important to note that the core question arrived at by the author in the conclusion of a literature review must agree with the core question announced in the essay's introduction. It can be stated, of course, in varying terms. But, if the key function of the introduction is to preview where the essay is ultimately going, the conclusion must, of course, demonstrate to the reader that the essay delivers what it promised.

A second common feature of a conclusion is the way in which the author can add up the gaps or omissions and questions unanswered by the current literature. This is also a very creative moment in the literature review process. While the author should eventually arrive at and justify a single core question to drive future research forward so as to reach escape velocity, the conclusion is an excellent place also to list any unanswered questions.

Finally, after articulating a substantial new and original core question based upon analysis of previous scholarship, the author is now entitled to offer their educated guess to a provisional thesis or answer to that new question. The reason 


\section{SLIS Student Research Journal}

July 2011, Vol.1, Iss. 1

that this is only an "educated guess" is because upon concluding a literature review the author has yet to gather and analyze new primary source data.

It is common for students to shy away from developing or asserting their own views at this point. While this is understandable to some degree, developing your professional point-of-view and volition is very important. Base your opinions of what might be investigated or researched next from what you have read and examined. After completing a thorough literature review you are informed enough about the scholarship to render an educated guess. Further, without the advantage of applying actual data to the new question it is impossible to be "wrong." After having read, analyzed, and synthesized the recent literature one is entitled to form and express an opinion. Seize that moment!

\section{Using our Student Research Journal}

This is the role our new Student Research Journal can play in the LIS field - a meaningful role in documenting graduate student views about "where the field is" and where they believe it needs to go. A successful literature review remains one of the best ways in which to achieve this escape velocity. Our $S R J$ thus offers you, as an emerging professional, a unique opportunity to directly apply your analytical skills both in exercising your professional volition and voice, as well as charting a new direction for the scholarship in our field: articulating a direction in which the field should take the next "turn."

As the faculty advisor for the journal, and speaking on behalf of the Editorial Advisory Board, we heartily invite you to take advantage of this opportunity. We welcome your contribution to advancing scholarly conversations and contributing to the School's developing community of research. 